OPEN ACCESS

Edited by:

Frans H. J. Claas,

Leiden University, Netherlands

Reviewed by:

Stanislaw Stepkowski, University of Toledo, United States Wai Lim,

University of Western Australia, Australia

*Correspondence: Oriol Bestard

obestard@bel/vitgehospital.cat

${ }^{+}$These authors have contributed equally to this work

Specialty section:

This article was submitted to Alloimmunity and Transplantation,

a section of the journal

Frontiers in Immunology

Received: 29 October 2020

Accepted: 31 December 2020

Published: 10 March 2021

Citation:

Meneghini M, Crespo E, Niemann M,

Torija A, Lloberas N, Pernin V, Fontova $P$, Melilli E, Favà A, Montero N, Manonelles A, Cruzado JM, Palou E, Martorell J, Grinyó JM and Bestard O (2021) Donor/Recipient HLA Molecular

Mismatch Scores Predict Primary Humoral and Cellular Alloimmunity in Kidney Transplantation.

Front. Immunol. 11:623276. doi: 10.3389/fimmu.2020.623276

\section{Donor/Recipient HLA Molecular Mismatch Scores Predict Primary Humoral and Cellular Alloimmunity in Kidney Transplantation}

\author{
Maria Meneghini ${ }^{1,2 \dagger}$, Elena Crespo ${ }^{2 t}$, Matthias Niemann ${ }^{3}$, Alba Torija ${ }^{2}$, Nuria Lloberas ${ }^{2}$, \\ Vincent Pernin ${ }^{2,4,5}$, Pere Fontova ${ }^{2}$, Edoardo Melilli ${ }^{1}$, Alexandre Favà ${ }^{1,2}$, Nuria Montero ${ }^{1}$, \\ Anna Manonelles ${ }^{1}$, Josep Maria Cruzado ${ }^{1,2}$ Eduard Palou $^{6}$, Jaume Martorell ${ }^{6}$, \\ Josep Maria Grinyó ${ }^{1,2}$ and Oriol Bestard ${ }^{1,2 *}$ \\ ${ }^{1}$ Kidney Transplant Unit, Nephrology Department, Bellvitge University Hospital, Barcelona, Spain, ${ }^{2}$ Translational Transplantation \\ and Nephrology Laboratory, Institut d'Investigació Biomèdica de Bellvitge (IDIBELL), Barcelona, Spain, ${ }^{3}$ Director of Technology, \\ PIRCHE-II AG, Berlin, Germany, ${ }^{4}$ Department of Nephrology, Dialysis and Transplantation, Montpellier University Hospital, \\ Montpellier, France, ${ }^{5}$ Institute for Regenerative Medicine \& Biotherapy (IRMB), University of Montpellier, INSERM, Montpellier, \\ France, ${ }^{6}$ Laboratory of Immunology and Histocompatibility, Hospital Clinic, Barcelona, Spain
}

Donor/recipient molecular human leukocyte antigen (HLA) mismatch predicts primary Bcell alloimmune activation, yet the impact on de novo donor-specific T-cell alloimmunity (dnDST) remains undetermined. The hypothesis of our study is that donor/recipient HLA mismatches assessed at the molecular level may also influence a higher susceptibility to the development of posttransplant primary T-cell alloimmunity. In this prospective observational study, 169 consecutive kidney transplant recipients without preformed donor-specific antibodies (DSA) and with high resolution donor/recipient HLA typing were evaluated for HLA molecular mismatch scores using different informatic algorithms [amino acid mismatch, eplet MM, and Predicted Indirectly Recognizable HLA Epitopes (PIRCHEII)]. Primary donor-specific alloimmune activation over the first 2 years posttransplantation was assessed by means of both dnDSA and dnDST using single antigen bead (SAB) and IFN- $\gamma$ ELISPOT assays, respectively. Also, the predominant alloantigen presenting pathway priming DST alloimmunity and the contribution of main alloreactive T-cell subsets were further characterized in vitro. Pretransplantation, 78/169 (46\%) were DST+ whereas 91/169 (54\%) DST-. At 2 years, 54/169 (32\%) patients showed detectable DST responses: 23/54 (42\%) dnDST and 31/54 (57\%) persistently positive (persistDST+). 24/169 (14\%) patients developed dnDSA. A strong correlation was observed between the three distinct molecular mismatch scores and they all accurately predicted dnDSA formation, in particular at the DQ locus. Likewise, HLA molecular incompatibility predicted the advent of dnDST, especially when assessed by PIRCHE-\| score (OR 1.014 95\% Cl 1.001-1.03, $\mathrm{p}=0.04$ ). While pretransplant DST predicted the development of posttransplant BPAR (OR 5.18, 95\% $\mathrm{Cl}=1.64-16.34, \mathrm{p}=0.005$ ) and particularly $T$ cell mediated rejection (OR 5.33, 95\% Cl=1.45-19.66, $p=0.012$ ), patients developing dnDST were at significantly higher risk of subsequent dnDSA formation 
(HR 2.64, 95\% $\mathrm{Cl}=1.08-6.45, \mathrm{p}=0.03)$. In vitro experiments showed that unlike preformed DST that is predominantly primed by CD8+ direct pathway T cells, posttransplant DST may also be activated by the indirect pathway of alloantigen presentation, and predominantly driven by CD4+ alloreactive $T$ cells in an important proportion of patients. De novo donor-specific cellular alloreactivity seems to precede subsequent humoral alloimmune activation and is influenced by a poor donor/recipient HLA molecular matching.

Keywords: alloreactive, T cell, HLA mismatch, donor-specific antibodies, kidney transplantation

\section{INTRODUCTION}

Long-lasting survival of kidney transplantation is greatly challenged by both preformed and primary donor-specific humoral alloimmunity: the former preventing access to transplantation in sensitized patients, and the latter accelerating chronic rejection and premature graft loss $(1,2)$. Between 5 and $9 \%$ of kidney transplant recipients may develop de novo donor-specific antibodies (dnDSA) each year mainly against class-II human leukocyte antigens (HLA) $(3,4)$. This is of significant clinical relevance, being chronic antibody mediated rejection $(A B M R)$ one of the leading causes of death-censored graft loss that may explain to some extent why even with modern immunosuppression, long term graft survival has not improved in recent years (5).

Recent data show that a major determinant of primary humoral alloimmune activation relies on poor donor/ recipient HLA matching, especially in case of non-adherence or insufficient immunosuppression exposure $(4,6,7)$. Notably, while clinical histocompatibility assessment is still based on alphanumeric class-I/II allele matching, novel computed algorithms have refined its evaluation by assessing the mismatch (MM) degree at a molecular level (8). The definition of the molecular differences between donor and recipient HLA molecules has been an interesting field of research developed in the last decade that led to the creation of informatic algorithms available for research purposes and whose clinical impact on outcomes has been investigated. On the one hand, the calculation of the number of highly polymorphic aminoacids composing the mismatched donor HLA molecules (amino acid MM) has been proposed and showed to predict primary humoral responses $(9,10)$. Similarly, the HLAMatchmaker algorithm defines the count of specific mismatched polymorphic aminoacidic-residues within 3 Ångstroms radius (eplets) exposed on the HLA molecular surface and constituting the functional epitopes against which anti-HLA antibodies are directed (11). The number of eplets that are mismatched between donor and recipients can be calculated by the HLAMatchmaker software either at each HLA locus, by class (1 or 2 ) or as a cumulative number or "eplet MM load". Some but not all eplets have been "antibody verified" in vitro and since this process is ongoing, newer versions of the calculator are periodically released including the last updates on the eplets' repertoire. An increasing number of eplet MM has been shown to identify kidney transplant recipients at higher risk of developing dnDSA, antibody-mediated rejection (ABMR) and worse allograft survival (12-15). Furthermore, since dnDSA can only be produced by $\mathrm{B}$ cells activated by cognate interactions with indirectly primed alloreactive $\mathrm{T}$ cells that have previously recognized donor HLA antigens (16), another HLA matching algorithm was developed to predict the number of recognizable donor-HLA-derived peptides that can be processed and presented by recipient's HLA class-II molecules according to the physico-chemical characteristics of donor and recipient HLA molecules (PIRCHE-II). The PIRCHE-II score sums the number of these peptides and defines the risk of primary antidonor humoral alloimmune activation through indirect pathway of antigen presentation. In clinical studies, this score has also been associated to the risk of dnDSA formation and graft loss $(13,17)$.

While previous clinical reports suggest that alloreactive T-cell priming precedes humoral activation, $(4,18,19)$ there is no evidence yet showing the frequency of de novo donor-specific $\mathrm{T}$ cell alloimmune activation (dnDST) after kidney transplantation and its association with donor/recipient HLA molecular matching. Hence, we here investigated the association of distinct donor/recipient HLA molecular mismatch algorithms with the risk of dnDST activation as well as its influence on subsequent dnDSA formation. While there are no readily available tests to monitor the presence of donor-specific T-cell responses in the clinical setting, we used one of the most sensitive immune assays tracking circulating frequencies of donor-reactive memory/effector T cells, the IFN- $\gamma$ Enzyme-Linked ImmunoSpot (ELISPOT), which has been validated between different research consortiums $(20,21)$ and has shown important associations between preformed $\mathrm{T}$-cell alloimmune memory and posttransplant rejection risk (22-24). On the other hand, the development of single antigen beads using solid phase assays has revolutionized the field of humoral alloimmune riskstratification as the most reliable assay tracking anti-HLA antibodies in clinical practice (25). Therefore, to obtain a complete picture of the kinetics of posttransplant donorspecific alloimmune responses, we used these two immune assays to detect dnDST and dnDSA at different time points during the first 2 years after kidney transplantation. Finally, the role of main T-cell subsets accounting DST alloreactivity and the type of alloantigen presenting pathways priming dnDST in vitro 
were further assessed to characterize the predominant donorantigen $\mathrm{T}$-cell priming occurring after transplantation.

\section{MATERIAL AND METHODS}

\section{Patients of the Study}

As illustrated in Figure 1, between June 2014 and December 2016326 adult kidney transplants were performed. Out of them, multiorgan transplant recipients, $\mathrm{ABO}$ incompatible, and HLA identical transplant recipients, with preformed DSA, without available donor/recipient PBMCs and/or high-resolution HLA typing and those lost to follow-up were excluded from this study. Clinical data were collected prospectively during clinical followup. BPAR was defined according to latest BANFF classification (26). Graft loss was defined either as re-transplantation or return to chronic renal replacement therapy. Minimum patient followup was 2 years (mean: $33 \pm 16$ months, range 24-60). All patients signed informed consent to participate in the study, which had been previously approved by the local Investigator Research Board.

\section{HLA Typing and Donor/Recipient Mismatch Scores HLA Typing}

High-resolution donor and recipient HLA typing was done for both class-I (A, B, C) and class-II (DRB1, DQB1, DPB1) antigens with NGS technology. Exons 2, 3, 4 for class I and exons 2 and 3 for class II were amplified by multiplex PCR. NGS was performed on a MiSeq platform (Illumina, San Diego, California). DRB3/4/and DPA1 could not be assessed in all donor/recipient pairs because of insufficient biological material, thus HLA mismatch scores were performed at A, B, C, DRB1,
DQB1 and DPB1 loci. Notably, since all recipients could be typed for DQA1, we evaluated PIRCHE score also taking into account the alloantigen presentation by recipients' $\mathrm{DQ}(\mathrm{B} 1 / \mathrm{A} 1)+$ DRB1 molecules.

\section{Amino Acid HLA Mismatches}

The HLA epitope mismatch algorithm (HLA-EMMA) was used to assess polymorphic amino acids on mismatched donor HLA molecules as previously described (27). Both total amino acid sequences and amino acids in solvent accessible positions were assessed as a global score and at the single HLA locus or molecule. The software package is available at http://www. HLA-EMMA.com.

\section{HLAMatchmaker Algorithm}

The HLAMatchmaker program (Rene Duquesnoy, 2016, University of Pittsburgh Medical Center, Pittsburgh, PA HLAABCEpletMatchingVersion3.1 and DRDQDPEpletMatching ProgramV3.1 from http://www.epitopes.net/downloads.html) was used to calculate eplet scores as previously described (6). Total number of eplet and antibody verified eplet mismatches were calculated for all HLA molecules (eplet MM load), for each locus and for each donor HLA molecule separately.

\section{Predicted Indirectly Recognizable HLA Epitopes II Algorithm}

PIRCHE-II score was calculated as previously described using the latest version3.3 from https://www.pirche.org (28). Briefly, the NetMHCIIpan3.0 algorithm was used to predict the nonameric-binding cores of donor mismatched HLA-derived peptides that can bind to recipient HLA-DRB1. Relevant HLADRB1 binders were defined as peptides with an IC50<1,000nM for HLA-DRB1 (15).

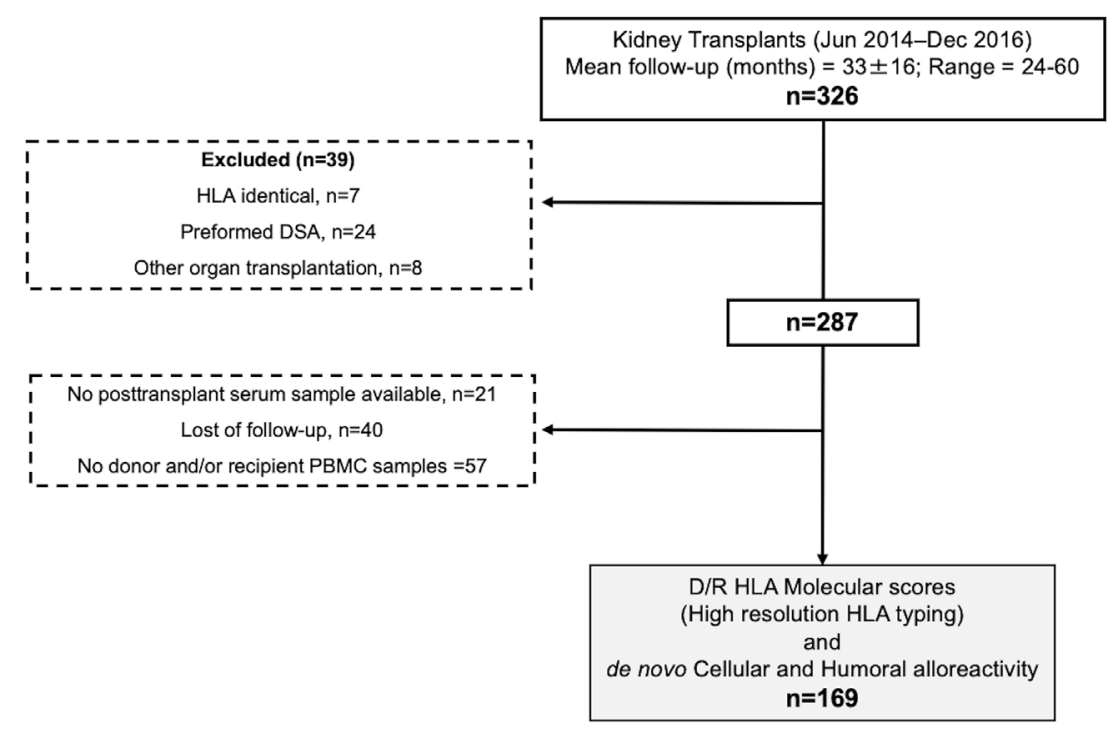

FIGURE 1 | Flow chart of the study. PBMCs, peripheral blood mononucleated cells; DSA, donor specific antibody. 
Donor-derived HLA class-II binder peptides that differed at least one amino acid in their non-americ-binding core from recipient's HLA sequence were counted as PIRCHE-II. Donor epitope-HLA complexes that were present multiple times in a donor/recipient couple were counted as a single PIRCHE-II. The analysis of PIRCHE-II global score enumerates all class I/ II donor derived peptides, presented by recipient DRB1 molecule. The peptide counts originated from each donor's locus and each donor molecule is also described. The analysis of DRB1 and DQ presentation of donor-derived peptides, and different IC50 cut-offs for peptide binding, were evaluated.

\section{Anti-HLA Antibody Determinations}

Patients' sera were tested for the presence of class-I and II antiHLA IgG antibodies at baseline, 6 and 12 months after transplantation and annually thereafter. A single-antigen classI and class-II flow beads-assay kit was used (LIFECODES, division of Immucor, Stanford, CA). All beads showing a normalized MFI $>500$ were considered positive if (MFI/MFI lowest bead) $>5$.

\section{Donor and Recipient Peripheral Blood Mononuclear Cell Samples Preparation and Evaluation of Circulating Donor- Specific T-Cell Alloreactivity Donor and Recipient Peripheral Blood Mononuclear Cell Samples}

Recipient and donor PBMCs from living donors or splenocytes from deceased donors were harvested and isolated by Ficoll density gradient centrifugation. Donor samples were depleted from T-Cells using either anti-CD3 (Human CD3+Cell Depletion Kit-RosetteSep Kit, STEMCELL, France) or antiCD2 kits (EasySep1 Human-CD2 Selection Kit, STEMCELL, France), in living or deceased donors, respectively, to avoid any donor T-cell alloimmune response. All samples were frozen in liquid nitrogen at $-80^{\circ} \mathrm{C}$ until their use.

\section{Evaluation of Donor-Specific Alloreactive T-Cell Responses}

The assessment of DST in peripheral blood, both prior and posttransplantation, was done using the IFN- $\gamma$ Enzyme-linked Immunosorbent Spot (ELISpot) assay as previously described (21). Briefly, $3 \times 10^{5}$ responder PBMC were placed in each Elispot well plate coated with primary IFN- $\gamma$ antibody wells with $3 \times 10^{5}$ donor cells, in triplicates. A negative control (complete medium alone: RPMI 1640, GE Healthcare Life Sciences, USA, with $10 \%$ inactivated FBS, antibiotics and Lglutamine) and a positive control (Pokeweed, AID, Autoimmun Diagnostika) were also tested in duplicates. Incubation time was $22 \mathrm{~h}$ at $37^{\circ} \mathrm{C}, 5 \% \mathrm{CO} 2$. Results were expressed as frequencies of IFN- $\gamma$ producing T-cells $/ 3 \times 10^{5}$ PBMCs, subtracting responses from negative donor and recipient control wells. As previously reported, a cut off of $\geq 25$ spots $/ 3 \times 10^{5}$ PBMCs was considered positive $(21,29)$.

\section{Analysis of T-Cell Receptor Dependent Activation-} Induced T-Cell Markers

To assess the contribution of CD8 and/or CD4 T-cell subsets to the allogenic $\mathrm{T}$-cell response assessed in vitro, 22 donor-recipient pairs with remaining available samples (pretransplant DST-, $\mathrm{n}=5$; pretransplant DST,$+ \mathrm{n}=10 ; \mathrm{dnDST}+, \mathrm{n}=7$ ) were tested in a T-cell receptor (TCR)-dependent Activation-Induced T-Cell Markers (AIM) assay as previously described (30).

Cells were cultured in 96-wells round bottom plates at $3 \times 10^{5} \mathrm{PBMC}$ per well either with $100 \mu \mathrm{l}$ of medium (negative control), $3 \times 10^{5} \mathrm{~T}$-cell depleted donor cells (allo-stimulation) or $50 \mu \mathrm{l}$ of phytohemagluttinin-PHA (positive control). After incubation, cells were stained with the following antibodies: CD4-FITC, CD8-APC-H7, CD134 (OX-40Antigen)-PE, CD69 (very early activation antigen)-PE-Cy7, CD137 (4-1BB)-APC, 7AAD (BD Biosciences, San Diego, CA). Donor Cells after $22 \mathrm{~h}$ incubation with medium were stained with CD4-FITC, CD8APC-H7 antibodies to test effective T-cell depletion. After $22 \mathrm{~h}$ incubation with T-cell depleted donor cells, we assessed by flow cytometry analysis the \% of AIM+ cells defined as the \% of $(\mathrm{CD} 69+\mathrm{CD} 137+)$ cells for CD8+ T cells, and (CD134-OX40+ CD137+) for CD4+. T-cell activation results are presented by subtracting the percentage of AIM+ cells after stimulation with medium (negative control) from \% of AIM+ cells after allogenic stimulation.

Flow cytometry was performed on a FACS-Canto flow cytometer and analyzed using the FACS-Diva Software (BD Biosciences, San Diego, CA).

\section{In Vitro Assessment of Alloantigen-Presenting Pathways Priming Donor-Specific T Cells}

In order to characterize the predominant alloantigen-presenting pathways of circulating DST in vitro, a subset of DST+ patients with available cell samples, either prior and/or after transplantation were functionally re-evaluated (preDST,$+ \mathrm{n}=9$; dnDST,$+ n=9$; persistDST+, $n=9$ ). For these experiments we modified the functional immune assay by evaluating in the same patient DST responses with the following conditions: 1) using total recipient PBMC as responder cells co-cultured with T-cell depleted donor stimulating cells and, 2) using recipient T-Cells only after being selectively isolated as responder cells co-cultured with donor stimulating cells. In the first assay, both directly and indirectly primed DST frequencies are detected, since recipient PBMCs include T cells (CD3+), B cells (CD19+), monocytes (CD14+) and dendritic cells (HLADR+CD14- CD3- CD19CD56-) (Supplementary Figure 1), whereas in the second experiment only $\mathrm{T}$ cells are present as responders thus, DST frequencies primed by the direct pathway (DP) of antigen presentation may be only detected. For these later experiments, a positive selection of recipient CD3+ T-Cells was done (Human T Cell Enrichment Kit-RosetteSep Kit, STEMCELL, France). Importantly, the same number of CD3+ T-Cells present in the all PBMCs sample was seeded in each well when analyzing the DST with enriched responder T-Cells, to avoid any additional response due to higher presence of responder T-Cells. Therefore, to assess the relative role of indirectly primed (IP) DST cells in 
the in vitro assays, the total number of IFN- $\gamma$ spots observed in the DP experiment was subtracted from those observed in the same patient when using all PBMCs as responder cells. PBMC subsets were stained with combinations of the following fluorochrome conjugated antibodies: CD3-APC-H7, CD19FITC, CD14-PECy7, CD56-PE, HLADR-APC (BD Biosciences, San Diego, CA).

\section{Statistical Analysis}

All continuous data are presented as mean \pm SD or median and interquartile-range. Different groups were compared using $\mathrm{X}^{2}$ test for categorical variables and student t-test for normally distributed data, and non-parametric Kruskal-Wallis or MannWhitney U test for non-normally distributed variables. Bivariate correlation analyses were performed by Pearson or Spearman test (non-parametric variables). Univariate and multivariate logistic regression analyses were used to determine the variables associated with the risk of developing BPAR and dnDST. The time-dependent association of the variables assessed on graft survival and dnDSA development was studied with Cox proportional hazard, Kaplan-Meier plots, and log-rank test. The statistical significance level was defined as 2-tailed $\mathrm{p}<0.05$. Statistical analyses were performed with IBM SPSS Statistics, version 26 (Armonk, NY) and GraphPad Prism version6.0 (GraphPad Software, La Jolla, CA).

\section{RESULTS}

\section{Patients of the Study and Main Clinical Outcomes}

As illustrated in Figure 1, 169 consecutives non HLA-identical, single, adult transplant recipients at Bellvitge University Hospital (Barcelona, Spain) without preformed DSA and in whom both donor and recipient HLA typing was characterized using high resolution Next Generation Sequencing (NGS) technology and peripheral blood mononuclear cells (PBMC) to monitor DST were obtained both prior and at different time points after transplantation were evaluated in this study.

As shown in Table 1, the patients included in the study were representative of the total kidney transplant patients performed during the study timeline, as there were no differences regarding main demographic, immunological, and clinical outcomes. Most patients of the study were male, Caucasic transplant recipients receiving a deceased donor kidney. Induction immunosuppression was mainly based on basiliximab induction with tacrolimus-based maintenance triple therapy.

Forty-six (27\%) patients developed delayed graft function (DGF) and 19 (11\%) biopsy-proven acute rejection (BPAR) (79\% TCMR, 21\% ABMR). 24/169 (14\%) patients developed dnDSA: 6 (25\%) class-I only (2 against A, 3 anti-B and 1 anti-C), 19 (80\%) class-II only (anti-DR $\mathrm{n}=1,5 \%$; anti-DQ $\mathrm{n}=17,89 \%$, anti-DP $\mathrm{n}=1,5 \%)$, and $1(5 \%)$ patient against both class-I and II. Five (21\%) patients developed dnDSA against both donor DQ molecules, thus the majority of dnDSA were directed against DQ antigens $(22 / 30,73 \%)$. Mean time until first dnDSA
TABLE 1 | Main baseline and clinical outcomes of the study population and comparison with patients not included in the study.

\begin{tabular}{|c|c|c|c|}
\hline $\begin{array}{l}\text { Main baseline } \\
\text { characteristics }\end{array}$ & $\begin{array}{l}\text { All patients } \\
(n=169)\end{array}$ & $\begin{array}{l}\text { Not studied } \\
\text { patients } \\
(n=118)\end{array}$ & $\mathrm{p}$ \\
\hline Recipient age (years) & $52 \pm 14$ & $52 \pm 14$ & 0.83 \\
\hline Recipient gender (male) & $110(65)$ & $30(25)$ & 0.09 \\
\hline Race (Caucasic) & $158(94)$ & $113(96)$ & 0.41 \\
\hline \multicolumn{4}{|l|}{ Cause of end stage disease } \\
\hline Vascular & $20(12)$ & $21(18)$ & 0.12 \\
\hline Diabetes & $8(5)$ & $14(12)$ & \\
\hline Glomerular & $48(28)$ & $30(25)$ & \\
\hline Polycystic kidney disease & $23(14)$ & $16(14)$ & \\
\hline Interstitial disease & $24(14)$ & $11(9)$ & \\
\hline Others/unknown & $46(27)$ & $26(22)$ & \\
\hline Time on dialysis (months) & $25 \pm 34$ & $21 \pm 25$ & 0.23 \\
\hline Transplant type (deceased) & $115(68)$ & $88(75)$ & 0.23 \\
\hline Donor age (years) & $55 \pm 15$ & $54 \pm 12$ & 0.86 \\
\hline Transplant number (1) & $152(90)$ & $106(90)$ & 0.98 \\
\hline Cold ischemia time (hours) & $12.8 \pm 9.5$ & $11 \pm 9$ & 0.18 \\
\hline \multicolumn{4}{|l|}{ Pre-transplant anti-HLA } \\
\hline Class I & $14(8)$ & $10(8.5)$ & 0.34 \\
\hline Class ॥ & $17(10)$ & $12(10.2)$ & 0.30 \\
\hline cPRA (maximum) & $2.8 \pm 6.6$ & $2.6 \pm 5.9$ & 0.88 \\
\hline \multicolumn{4}{|l|}{ Main immunosuppression } \\
\hline \multicolumn{4}{|l|}{ (rATG/basiliximab/none) } \\
\hline $\begin{array}{l}\text { - Maintenance therapy (CNI, } \\
\text { tacrolimus) }\end{array}$ & $150(89)$ & $116(98)$ & 0.06 \\
\hline $\begin{array}{l}\text { - Steroid withdrawal before } 6 \\
\text { months (yes) }\end{array}$ & $50(30)$ & $38(34)$ & 0.41 \\
\hline \multicolumn{4}{|l|}{ Main clinical outcomes } \\
\hline DGF & $46(27)$ & $36(31)$ & 0.54 \\
\hline BPAR & $19(11)$ & $17(14)$ & 0.43 \\
\hline$T C M R / A B M R$ & $15 / 4$ & $16 / 1$ & $0.21 / 0.33$ \\
\hline $\begin{array}{l}\text { Patients developing de novo } \\
\text { DSA }\end{array}$ & $24(14)$ & 20 & 0.49 \\
\hline HLA class I & 6 & 3 & \\
\hline HLA class ॥ & 19 & 18 & \\
\hline HLA class I and II & 1 & 1 & \\
\hline Death-censored graft loss & $9(5)$ & $10(9)$ & 0.32 \\
\hline Patient death & $11(6)$ & $4(4)$ & 0.24 \\
\hline
\end{tabular}

Data are mean (standard deviation, $S D$ ) or $n(\%)$.

CPRA, calculated panel of reactive antibodies; rATG, rabbit anti thymoglobulin; CNI, calcineurin inhibitor; BPAR, biopsy-proven acute rejection; TCMR, T cell mediated rejection; $A B M R$, antibody-mediated rejection; DSA, donor-specific antibodies.

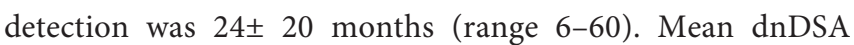
mean fluorescence intensity (MFI) was 8,685 (range 1,152-20,338).

Death-censored graft loss occurred in $9(6 \%)$ patients, being main causes BPAR (5,55\%), interstitial fibrosis/tubular atrophy (2, 22\%), primary glomerulonephritis recurrence $(2,22 \%)$. Eleven (6\%) patients died with a functioning graft because of malignancies $(5,45 \%)$, infections $(3,27 \%)$, and cardiovascular events $(3,27 \%)$.

A detailed description of the different HLA mismatch (MM) scores of the study population is depicted in Supplementary Table 1. Despite the strong positive correlation between the three molecular MM algorithms, a single number of HLA allelic mismatch could correspond to a wide range of molecular MM at the individual patient level (Supplementary Figure 2).

No direct association was observed between BPAR and the HLA allelic, amino acid, and eplet MM scores (OR 1.08, 95\% CI 
0.84-1.38, $\mathrm{p}=0.54$ allelic; OR 1.01, 95\% CI 0.99-1.04, $\mathrm{p}=0.33$ global amino acidic and OR 1.02, 95\% CI 0.98-1.07, p=0.34 eplet $\mathrm{MM}$ ), but for global PIRCHE-II score (OR 1.012, 95\% CI 1.0011.023, $\mathrm{p}=0.038$ ). Patients developing ABMR during follow-up showed a trend towards higher amino acid MM $(88 \pm 5$ vs. $63 \pm 22$, $\mathrm{p}=0.08)$; global PIRCHE-II ( $117 \pm 48$ vs. $80 \pm 38, \mathrm{p}=0.06)$ and higher eplet MM load (41.5 \pm 7 vs. $32 \pm 11, \mathrm{p}=0.07)$. There was no effect of molecular MM scores on graft function progression, death-censored graft survival, and patient death (data not shown).

\section{Donor/Recipient HLA Molecular Mismatch Scores Predict Primary Humoral Alloimmunity}

As shown in Figure 2, significantly higher MM scores of each molecular algorithm against the individual mismatched donor DQ molecule was observed for the respective anti-DQ dnDSA. No association was observed at the allelic MM level (data not shown). A similar association was observed when donor DQ peptides presented by both recipient DRB1 and DQ were assessed $(35.19 \pm 29$ vs. $17.70 \pm 23, \mathrm{p}=0.0002$, in $\operatorname{dnDSA}+v s$. dnDSA-, respectively). We did not study the impact of the different molecular algorithms in the two solely anti-DP and anti-DR dnDSA. A positive correlation with anti DQ dnDSA MFI was observed for DQB1 amino acid MM ( $r=0.57, p=0.02$; solvent accessible $r=0.60, p=0.013), D Q B 1$ eplet $M M(r=0.44$, $\mathrm{p}=0.03)$, and DQB1 PIRCHE-II score $(\mathrm{r}=0.36, \mathrm{p}=0.08)$.

\section{Donor/Recipient HLA Molecular Mismatch Scores and Primary T-Cell Alloimmunity Pretransplant DST Does Not Correlate With Donor/ Recipient HLA Molecular MM Scores}

Despite the absence of preformed DSA, 78/169 (46\%) showed high frequencies of pretransplant DST (preDST+), whereas 91 (54\%) did not (preDST-). No association was found between preDST+ and main clinical, demographic characteristics nor with different HLA molecular MM scores (Supplementary Table 2). Nonetheless, preDST+ patients showed higher risk of BPAR (OR 5.18, 95\% CI=1.64-16.34, $\mathrm{p}=0.005$ ), mostly TCMR (OR 5.33, 95\% $C I=1.45-19.66, p=0.012$ ) (Supplementary Figure 3), whereas it was not associated with dnDSA nor death-censored graft survival. Multivariate logistic regression analysis showed that while PIRCHE-II and tacrolimus CV (OR 1.02, 95\% CI $1-1.04, \mathrm{p}=0.047$ ) where associated to BPAR, only preDST+, induction therapy with rATG and DGF were independent correlates of BPAR (preDST+ OR 8.46, 95\% CI 1.7-41.8, $\mathrm{p}=0.009$; rATG induction OR $0.13,95 \%$ CI $0.14-1.3, \mathrm{p}=0.08$; DGF OR 3.9, 95\% CI 1.2-13.1, $\mathrm{p}=0.03$ ).

\section{PIRCHE-II Score Identifies Patients at Risk of Primary Donor-Specific T-Cell Alloreactivity}

After transplantation, 54/169 (32\%) patients showed DST responses at some timepoint (postDST+), being $23(42 \%)$ dnDST and $31(57 \%)$ persistently positive (persistDST+), whereas 115/169 (68\%) were postDST- (68 preDST- and 47 preDST + ) (Figure 3A). Changes of mean donor-reactive IFN- $\gamma$ $\mathrm{T}$-cell frequencies between pre and posttransplantation are depicted in Figures 3B-E.

While none of the different HLA MM scores associated with postDST+ (persistDST+ and/or dnDST+) (data not shown), a significantly higher global PIRCHE-II score was observed among dnDST+ than within postDST- patients (Figure 4). When analyzing the single HLA loci, dnDST patients showed significantly higher solvent-accessible DRB1 amino acid MM, not-Ab-verified (Abv) DRB1 eplet MM, PIRCHE-II DRB1, and PIRCHE-II DQB1 (DRB1 amino acid MM $11.17 \pm 6.2$ vs. $8.18 \pm$ 6.4, $\mathrm{p}=0.05$, not-Abv DRB1 Eplet $6.3 \pm 3.05$ vs. $4.79 \pm 3.5, \mathrm{p}=0.06$ PIRCHE-II DRB1 $15.5 \pm 11.9$ vs. $9.44 \pm 8.4, \mathrm{p}=0.03$, PIRCHE-II DQB1 $22.65 \pm 15.7$ vs. $16.29 \pm 12.5 \mathrm{p}=0.05)$. When assessing the PIRCHE-II score presented by DRB1+DQ molecules, similar results were observed, being the count of DRB1 donor-derived peptides similarly associated to dnDST activation (29.95 $\pm 24.2 v s$. $20.15 \pm 17.8, \mathrm{p}=0.04)$. However, the difference in global PIRCHE-II score presented by both DRB1+ DQ molecules was not statistically different (199.4 \pm 132 in dnDST $+v s .175 .1 \pm 91$ in dnDST-, $\mathrm{p}=0.4)$. The relationship between PIRCHE-II and dnDST for different peptide affinity thresholds (IC50: 0-50, 0-125, and 125-1,000), revealed that PIRCHE-II was significantly associated to dnDST especially at less stringent IC50 intervals (Supplementary Figure 4). Donor-specific T-cell frequencies did not correlate
A

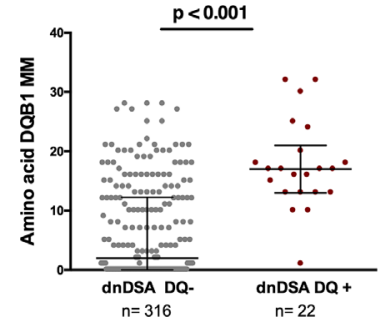

B

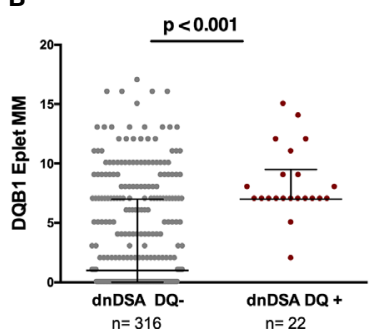

C

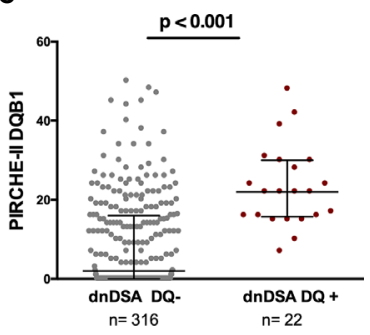

FIGURE 2 | Association between amino acid MM, eplet MM load, and PIRCHE-II score for each donor DQ molecule and the respective dnDSA formation. Each dot illustrates the single molecular MM score of each donor DQ molecule against which the patients developed or not dnDSA. (A) Amino acid MM $6.5 \pm 7.9$ vs $17.6 \pm$ 7.4, $\mathrm{p}<0.001$. Solvent accessible $4.82 \pm 6.18$ vs $12.87 \pm 6.29, \mathrm{p}<0.001$. (B) Eplet MM load $3.56 \pm 4.33$ vs $8.27 \pm 2.95$, p<0.001. Antibody-verified 1.31 \pm 1.87 vs $2.82 \pm 1.26,<0.001$. (C) PIRCHE-II $8.98 \pm 11.54$ vs $23.2 \pm 10.84$, p<0.001. MM, mismatch; dnDSA, de novo donor-specific antibody. 


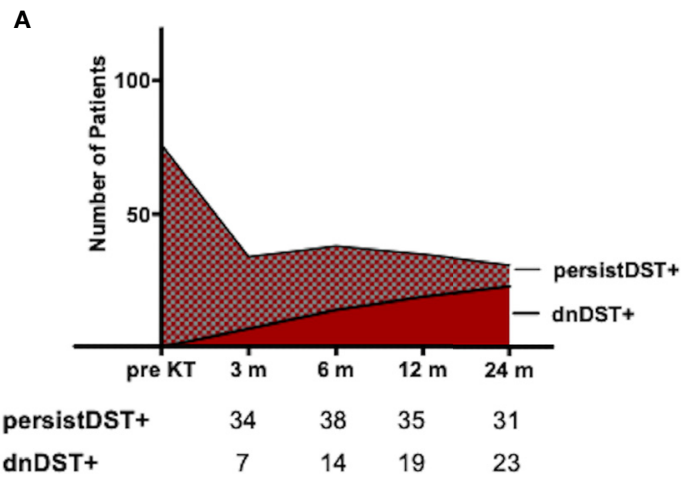

B

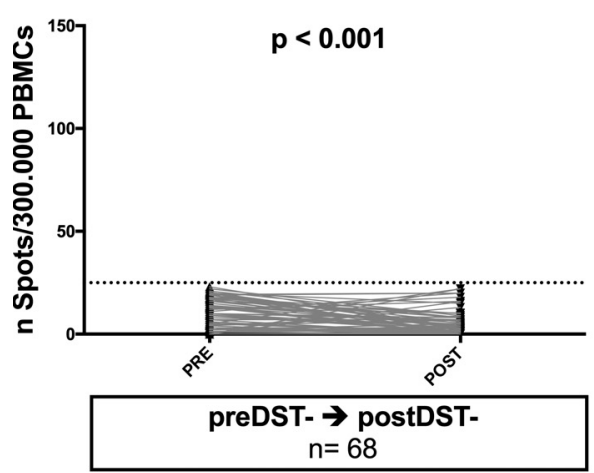

D

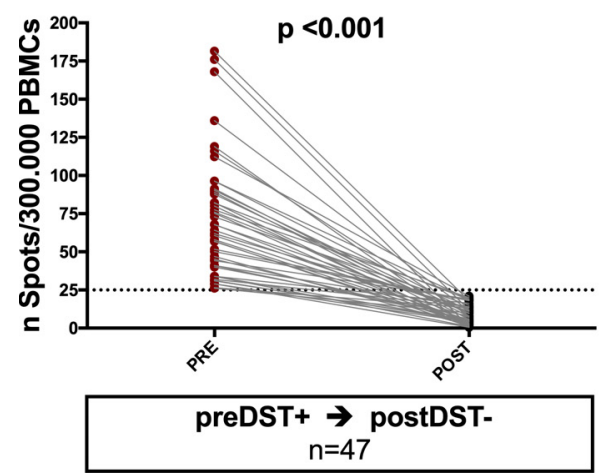

C

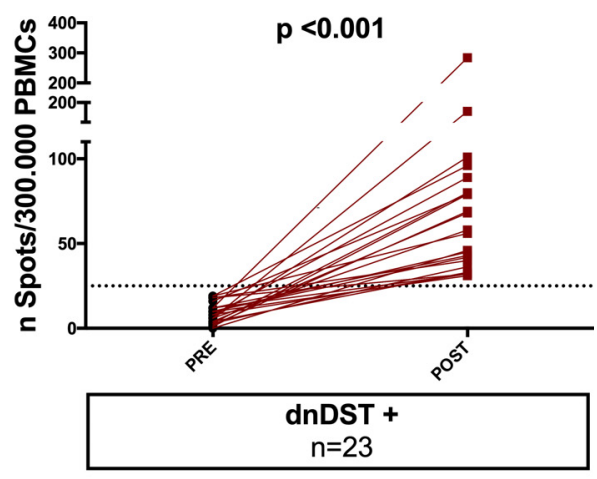

$\mathbf{E}$

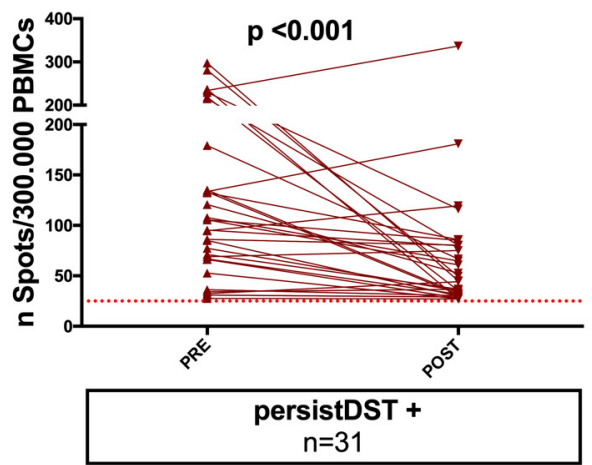

FIGURE 3 | Kinetics of posttransplant de novo DST and changes of mean donor-reactive IFN- $\gamma$ T-cell frequencies between pre and posttransplantation in different groups of patients. (A) At month 3, 6, 12, and 24 months 7, 7, 5, and 4 patients developed dnDST, and 34, 38, 35 and 31 were PersistDST+ respectively. (B-E) All preDST- remaining DST- and preDST+ becoming postDST- showed significantly lower T-cell frequencies posttransplantation. PersistDST+ although remaining positive, showed weaker responses. Only dnDST+ patients showed a significant increase of spots number. (B) preDST- and postDST-: preDST mean $9.76 \pm 7.2$ IFN- $\gamma$ spots/300.000 PBMC; postDST mean 5.28 \pm 6.27 IFN- $\gamma$ spots/300.000 PBMC (C) dnDST: postDST mean 70.7 \pm 55.9 spots/300.000PBMCs. (D) preDST+ and postDST-: preDST+ mean $67.04 \pm 35.9$ IFN- $\gamma$ spots/300.000PBMC; postDST: mean $8.76 \pm 6.35$ IFN- $\gamma$ spots/300.000 PBMC (E) persistDST+: postDST mean 66.56 \pm 61.04 IFN- $\gamma$ spots/300.000 PBMC. DST, donor specific T cell alloreactivity; preDST, pretransplant donor-specific T-cell alloimmune response; postDST, posttransplant donor specific T-cell alloreactivity; dnDST, de novo donor specific T-cell alloreactivity; persistDST, persistent donor specific T-cell alloreactivity.

with amino acid MM ( $\mathrm{r}=0.17, \mathrm{p}=0.14)$ nor Eplet MM load $(\mathrm{r}=0.1$, $\mathrm{p}=0.34$ ), whereas showed a weak but positive linear correlation with the global PIRCHE-II score $(\mathrm{r}=0.24, \mathrm{p}=0.025)$.

In the univariate and multivariate logistic regression analysis for the prediction of dnDST, high global PIRCHE-II score and delayed graft function were independent correlates (Table 2). Conversely, persistDST + was only predicted by absence of T-cell depletion (OR 0.09, 95\% CI 0.01-0.62, p=0.01) and high pretransplant IFN- $\gamma$ ELISpot frequencies (OR 1.02, 95\% CI 1.0091.03, $\mathrm{p}=0.001)$. 
A

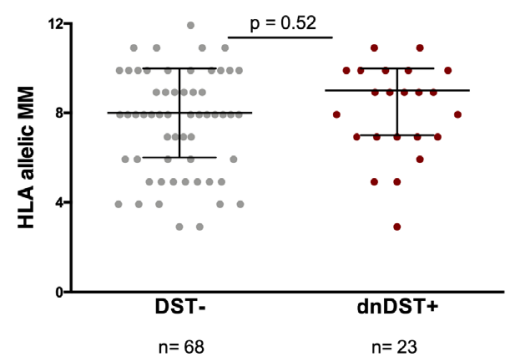

C

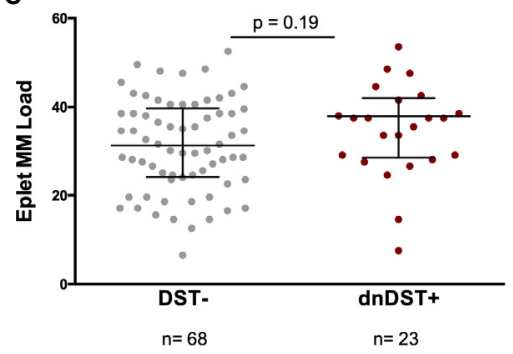

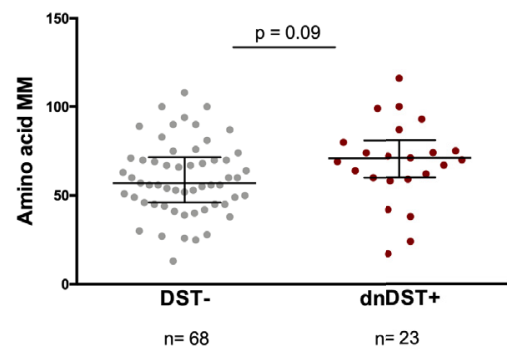

D

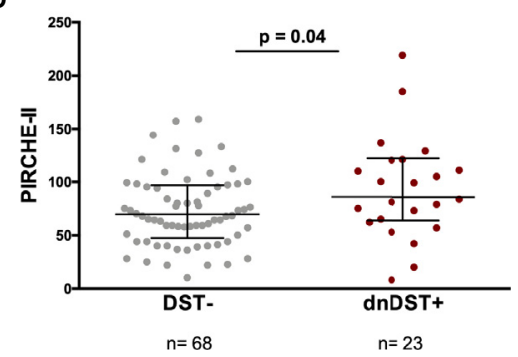

FIGURE 4 | HLA allelic MM, amino acid MM, eplet MM load, global PIRCHE-Il and de novo DST. Comparisons between HLA MM scores and dnDST- or dnDST+ patients. (A) HLA allelic MM $7.66 \pm 2.3$ vs $8.05 \pm 2.2, p=0.52$. (B) Amino acid MM $60.52 \pm 20.6$ vs $69.47 \pm 25.8, p=0.09$. (C) eplet MM load $31.62 \pm 10.5$ vs $35 \pm 10.5, p=0.19$. (D) PIRCHE-II $74.1 \pm 33.2$ vs $94.8 \pm 48.1, p=0.04$. MM, Mismatch; DST, donor specific.

TABLE 2 | Univariate and multivariate logistic regression for the risk of de novo donor-specific T-cell (dnDST).

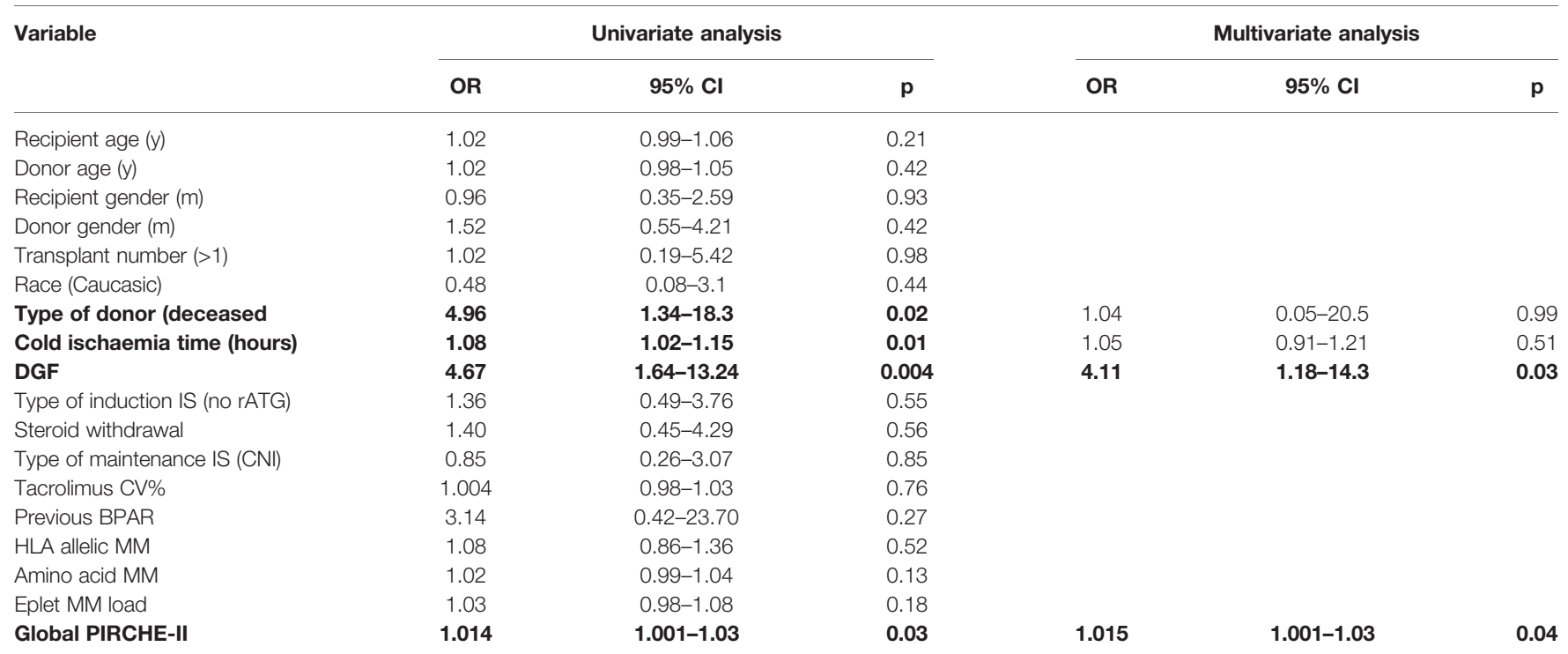

rATG, rabbit anti thymoglobulin; DGF, delayed graft function; CNI, calcineurin inhibitor; CV, coefficient of variation (CV = $\sigma / \mu \times 100)$; BPAR, biopsy-proven acute rejection; HLA, human leukocyte antigens; MM, mismatches; IS, immunosuppression; DST, donor-specific T-cell alloimmunity.

In bold are statistically significant variables.

\section{De Novo DST Predicts Subsequent Development of dnDSA}

While postDST + showed a higher risk of subsequent dnDSA formation ( $\mathrm{HR}$ 2.66, 95\% CI=1.19-5.95, p=0.017), when stratifying postDST in either persistent or de novo, dnDST displayed a stronger risk of dnDSA than persistDST (HR 2.64, 95\% CI $=1.08-6.44, \mathrm{p}=0.03$ and $\mathrm{HR} 1.62,95 \% \mathrm{CI}=0.63-4.13$, $\mathrm{p}=0.31$, respectively). Kaplan-Meier dnDSA-free survival curves illustrate the cumulative dnDSA rates among different postDST groups (Figure 5). 
A

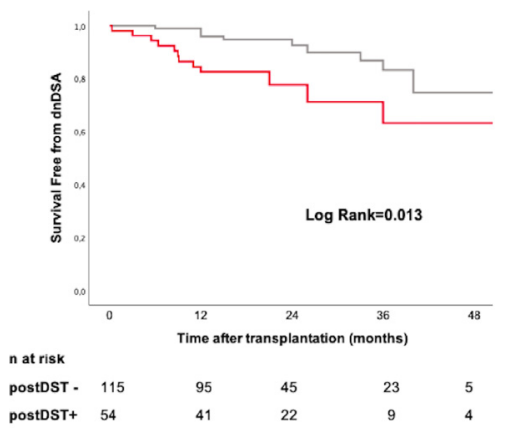

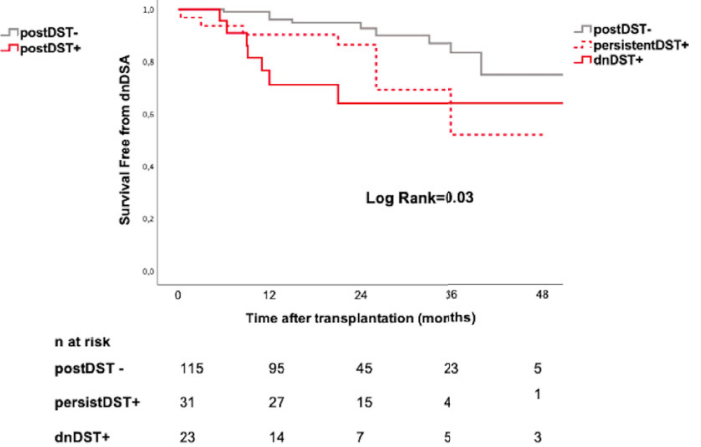

FIGURE 5 | Posttransplant donor-specific T-cell alloreactivity and de novo DSA formation. Kaplan-Meier curves illustrating the cumulative incidence of dnDSA stratified according to: (A) postDST - vs. postDST+ (B) postDST+ further stratified in dnDST or persistDST. postDST- vs. persistDST+= log rank 0.07; postDST- vs. dnDST + log rank=0.01; persistDST+ vs. dnDST+ log rank=0.36. dnDSA, de novo donor-specific antibody; DST, donor specific T-cell alloreactivity; postDST, posttransplant donor specific T-cell alloreactivity; dnDST, de novo donor specific T-cell alloreactivity; persistDST, persistent donor specific T-cell alloreactivity.

In addition, transplant patients with both dnDST+ and dnDSA+ showed significantly higher PIRCHE-II global score as compared to patients with either dnDST or dnDSA or those without dnDSA nor dnDST ( $101 \pm 49$ vs. $78.9 \pm 38, \mathrm{p}=0.04)$. No differences were observed with any of the other HLA molecular MM algorithms at this level.

While we did not observe any correlation between posttransplant IFN- $\gamma$ ELISpot frequencies and MFI of dnDSA (Rho $-0.7, \mathrm{p}=0.75$ ), a weak but statistically significant inverse correlation with 12 and 24month graft function was observed (eGFR 12 months $\mathrm{r}=-0.25$, $\mathrm{p}=0.01$; eGFR 24 months $\mathrm{r}=-0.20, \mathrm{p}=0.01)$.

\section{Higher Involvement of CD4+ T Cells in De Novo T-Cell Alloreactivity as Compared to Pretransplantation}

The contribution of CD8+ and CD4+ T cells to donor-reactive T-cell responses were investigated using the TCR dependent activation-induced cell marker (AIM) assay in a subset of patients. CD4+ and CD8+ AIM $+\mathrm{T}$ cells varied among different DST groups, which were detected both within preDST+ and dnDST+ patients (Supplementary Figure 5).

The percentages of CD8+ and CD4+ AIM+ T cells, were significantly higher among DST+ as compare to DST-
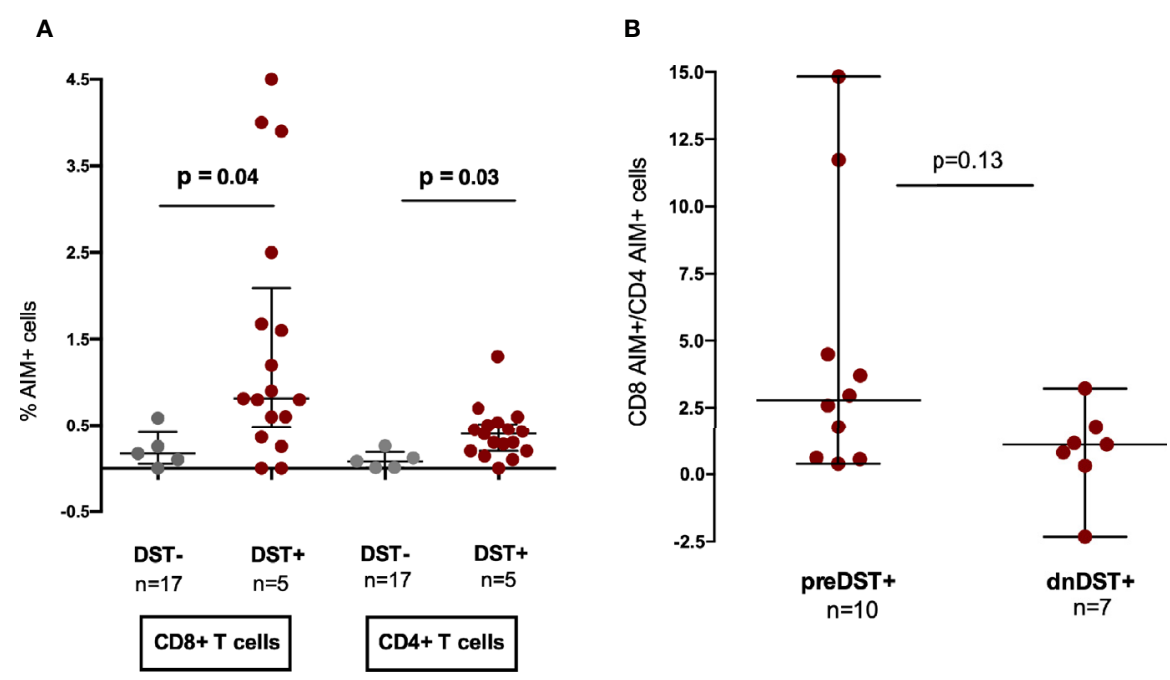

FIGURE 6 | Contribution of CD8 and CD4 T cell subsets to pre- and posttransplant donor-specific alloreactivity assessed by T-cell receptor dependent activationinduced cell markers (AlM) by flow cytometry analysis. (A) Comparison of \% of CD8+ AlM + T cells (CD69+CD137+) and AlM+ (OX40+CD137+) CD4+ T cells after allogenic (donor-specific stimulation) in DST- or DST+ patients. CD8+ AIM+: median 0.17\% (0.05-0.42) vs 0.81\% (0.48-2.09), $p=0.041 ; \mathrm{CD} 4+\mathrm{AlM}+$ : median 0.08\% (0.008-0.19) vs $0.40 \%(0.2-0.56), p=0.029$ in non alloreactive versus alloreactive patients, respectively. (B) CD8+/CD4+ AlM+ T-cell ratio in preDST+ and dnDST+ samples, respectively. Median $2.77(0.6-6.3)$ in preDST+ vs. $1.13(-2.3-1.79)$ in dnDST+, $\mathrm{p}=0.13$. AlM, T-cell receptor dependent activation-induced cell markers; DST, donor specific T-cell alloreactivity; preDST, pretransplant donor specific T-cell alloreactivity; dnDST, de novo donor specific T-cell alloreactivity. 
independently of the time of the IFN- $\gamma$ ELISpot test assessment, either before or after transplant (Figure 6A), confirming that the two assays are concordant detecting the same donor-reactive $\mathrm{T}$ cells. Notably, when we stratified for time of assessment, $d n \mathrm{DST}+$ showed a numerically lower CD8+/CD4+ AIM+ T-cell ratio than preDST+ suggesting an increased contribution of CD4+ alloreactive $\mathrm{T}$ cells after transplantation among dnDST+ patients (Figure 6B).

\section{Contribution of Distinct Alloantigen Presentation Pathways Priming Posttransplant Donor-Specific T-Cell Alloreactivity}

In order to characterize the contribution of the two main alloantigen presenting pathways, both direct (DP) and indirect (IP), priming circulating donor-reactive T cells, we functionally characterized them in vitro. When using whole recipient PBMC, different cell subsets other than $\mathrm{T}$ cells such as B cells, monocytes and dendritic cells were present, whereas only $\mathrm{T}$ cells were detectable when recipient PBMC were enriched for $\mathrm{T}$ cells (Supplementary Figure 1).

While most circulating preDST+ responses $[7 / 9,(78 \%)]$ were driven by donor-reactive T cells primed by the $\mathrm{DP}$, an important proportion of patients with postDST + responses, either dnDST + or persistDST+, were also primed by the IP $(5 / 9,55 \%$ in both groups) (Figure 7A). While no differences were found at the HLA allelic, aminoacidic and eplet MM scores, patients with IP_postDST + (either dnDST + or persistDST + ) showed a trend toward higher PIRCHE-II scores than those with only DP_DST+ (Figures 7B-E and Supplementary Table 3).

\section{DISCUSSION}

Primary humoral alloimmune activation through dnDSA production is a well-characterized deleterious factor inducing chronic ABMR and accelerated graft loss $(1,2)$ and recent reports have recently shown that it may be predicted by quantifying the donor/recipient HLA MM at the molecular level $(6,31)$. However, for B-cell activation in absence of preformed immune memory, cognate $\mathrm{T}$-cell help is required thus, previous de novo $\mathrm{T}$-cell alloimmune priming (dnDST) against donor antigens might also occur, subsequently driving anti-donor humoral immune activation.

In our study, we first confirm that HLA matching at the molecular level using distinct algorithms outperforms allelic MM assessment predicting primary humoral alloimmunity by means of dnDSA formation. Furthermore, we report that a relevant number of kidney transplant recipients develop dnDST after transplantation, which ultimately predicts the advent of dnDSA. Notably, unlike pretransplant DST, an important proportion of posttransplant DST patients, either those with persistent or de novo DST, display high frequencies of donor-reactive CD4+ T cells primed by the indirect antigen presentation pathway, which contributes to their global DST response. Most interestingly, and similarly to dnDSA, our data suggest that patients at risk of dnDST seem to also show a poor donor/recipient HLA molecular matching, and in particular, at the Predicted indirectly Recognizable HLA Epitopes II (PIRCHE-II) score level, emphasize the contribution of the indirect antigen presenting pathway driving DST development. These data highlight a continuous increased risk of $\mathrm{dnDST}$ and $\mathrm{dnDSA}$ for each
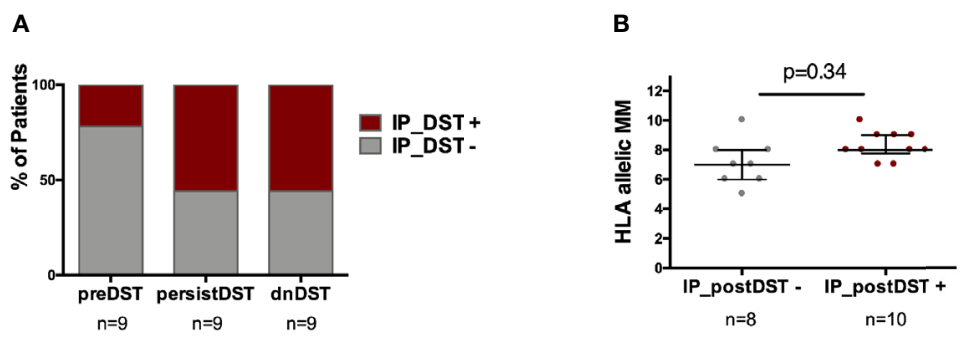

C

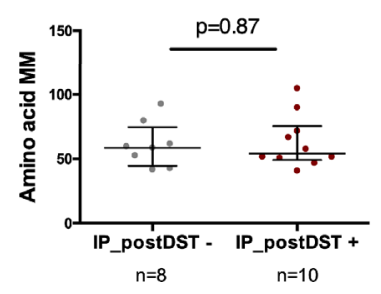

D

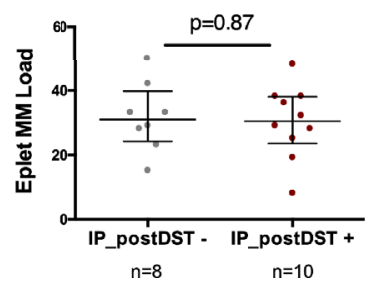

E

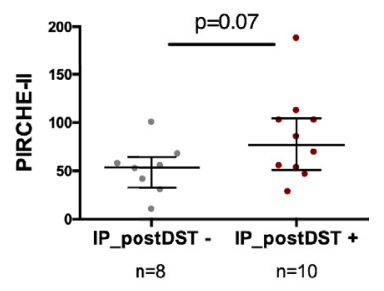

FIGURE 7 | Predominance of the type of alloantigen presenting pathway priming DST according to the time of DST assessment and association with distinct HLA MM scores. (A) Proportion of patients showing any degree of IP_DST+ according to timing of DST assessment (preDST $n=2 / 9,22 \%$; persistDST $n=5 / 9,56 \%$; or dnDST $n=5 / 9,56 \%)$. (B) Distribution of HLA allelic MM between IP_postDST- $(n=8)$ and IP_postDST+ patients ( $n=10): 7.12 \pm 1.5$ vs. $8.3 \pm 0.95, p=0.34$ (C) Amino acidic MM 60.5 \pm 17.5 vs. $62.5 \pm 20.4, p=0.87$ (D) Eplet MM load 31.6 \pm 10.8 vs. $30.1 \pm 11.2, p=0.87$ (E) PIRCHE- 1 51.5 \pm 26 vs. $83.9 \pm 45, p=0.07$. MM, mismatch; DST, donor specific T-cell alloreactivity; preDST, pretransplant DST; postDST, posttransplant donor specific T-cell alloreactivity; dnDST, de novo donor specific T-cell alloreactivity; IP DST, indirect pathway donor specific T-cell alloreactivity (with recipient APCs). 
individual predicted peptide presented by recipient APC through indirect presentation. This is, to our knowledge, the first report showing the impact of HLA molecular incompatibility on the development of primary adaptive alloimmunity, not only at the humoral but also at the cellular level in solid organ transplantation.

In order to track the presence of donor-reactive $\mathrm{T}$-cell responses, we used the IFN- $\gamma$ donor-specific T-cell ELISpot, a sensitive and reproducible immune-assay tracking circulating donor-reactive IFN- $\gamma$-producing memory/effector T cells (21, 32). Most studies using this test have focused on the pretransplant setting and have shown its capacity identifying transplant candidates at higher risk of $\mathrm{BPAR}$, regardless preformed donor-specific humoral immune sensitization (2224, 29). Here, while we confirm this observation, pretransplant DST was not associated with any HLA MM score thus, strongly suggesting that its presence may arise from either antigen crossreactivity amid heterologous immunity or prior transient alloantigen recognition triggering a low immune sensitization state, predominantly at the T-cell compartment. Notably, it has recently been reported the impact of HLA class-II mismatching predicting not only the advent of dnDSA and ABMR but also $\operatorname{TCMR}(14,33,34)$. In this regard, our findings support a mechanistic explanation of incompatibility at the DR and DQ molecules being especially associated to the risk of de novo T-cell activation. Although intuitively, a specific threshold would be of high relevance to help stratifying patients into high or low risk for either dnDSA or dnDST, from the biological point of view these thresholds might not represent the potential impact for alloimmune activation. Indeed, despite the strong correlation between the load of molecular MM and risk of de novo alloimmunity, even a small amount of mismatched antigens may be sufficient to activate an immune response, thus application of specific cut-offs may be misleading in clinical practice $(34,35)$.

Another important observation of our study is that up to $50 \%$ of transplant recipients with preDST maintained a strong DST response after kidney transplantation, which seems to be mainly influenced by pretransplant anti-donor T-cell frequencies and the absence of T-cell depletion induction therapy. Interestingly, a strong association was observed between postDST and subsequent dnDSA formation, particularly among dnDST patients. While we cannot confirm whether patients with persistent DST show the same pretransplant donor-reactive Tcell clones after transplantation, we observed that an important proportion of them did also display DST primed by the IP, similarly to patients with dnDST thus, suggesting that DST responses among persistDST may have also been developed de novo. Interestingly, dnDST was also influenced by the development of delayed graft function, which could possibly be explained by an inflamed milieu with increased class II HLA antigen expression on graft cells ultimately driving T-cell alloantigen recognition. The higher presence of alloreactive CD4+ T cells in dnDST + samples as compared to pretransplantation does also support that posttransplant antidonor alloreactivity is driven, at least also in part, by the IP of antigen presentation. While the presence of the IP after transplantation has been widely described $(16,36,37)$, a body of evidence has also shown the potential relevance of a semidirect or third pathway of antigen presentation (38-40). In this line, we also found circulating postDST responses primed by the $\mathrm{DP}$ when assessed in vitro, most likely representing the presence of such semidirect pathway of antigen presentation in vivo.

Our study has some limitations. The retrospective design may hamper achieving robust conclusions. Nonetheless, the use of high-resolution HLA typing and the significant associations observed together with the concomitant mechanistic in vitro experiments performed, counterbalance this drawback. Also, both DPA and DRB3/4/5 typing could not be assessed, leaving undetermined the impact of molecular MM at those loci on dnDST generation as well as their peptide presenting role. Nevertheless, the accurate prediction of dnDST by donorderived DRB1 peptides and also when evaluating DQ presentation strengthens the consistency of our findings. Notably, dnDST was accurately predicted by donor-derived DRB1 peptides but not by the global peptide burden if DQ presentation is evaluated. The expression of DQ molecules in recipient $\mathrm{APC}$ or different activation capacity of $\mathrm{CD} 4+\mathrm{T}$ cells according to distinct HLA class-II molecules may explain this observation.

In conclusion, we here show the impact of novel HLA molecular matching scores, also influencing a higher risk of primary anti-donor cellular alloimmune activation after kidney transplantation, which seems to precede the subsequent development of de novo humoral alloreactivity. Importantly, the value of implementing these novel donor/recipient HLA matching scores in kidney transplantation to refine current immune-risk stratification needs to be further explored in larger studies.

\section{DATA AVAILABILITY STATEMENT}

The raw data supporting the conclusions of this article will be made available by the authors, without undue reservation.

\section{ETHICS STATEMENT}

The studies involving human participants were reviewed and approved by Investigator Research Board Bellvitge University Hospital. The patients/participants provided their written informed consent to participate in this study.

\section{AUTHOR CONTRIBUTIONS}

OB: conceptualization of the study and supervision. OB, JG, MM, EM, AF, NM, AM, JC: clinical patients' follow-up. MM, EC, AT, NL, VP, PF: performed the experiments. MM, EC, OB: collected and organized the data and performed the statistical 
analysis. MN, EP, JM: supervised the HLA molecular MM analysis. $\mathrm{MM}$ and $\mathrm{OB}$ wrote the first draft of the manuscript. $\mathrm{OB}$ and JG reviewed the manuscript. All authors contributed to the article and approved the submitted version.

\section{FUNDING}

This work was supported by the Instituto de Salud Carlos III (ISCIII) (grant numbers ICI14/00242 and PI16/01321, PI19/ 01710) (co-funded by European Regional Development Fund, ERDF, a way to build Europe) ant the Biomarker-Driven Immunosuppression Minimization (BIO-DRIM) Consortium (EU FP7-health, grant agreement number 305147; FP7/20072013). Also, this work was partly supported by the SLT002/16/ 00183 grant, from the Department of Health of the Generalitat de Catalunya by the call "Acció instrumental de programes de recerca orientats en l'àmbit de la recerca i la innovació en salut." The authors thank the Research Centers of Catalonia (CERCA) Programme/Generalitat de Catalunya for institutional support. OB was awarded with an intensification grant from the "Instituto de Salud Carlos III" [INT19/00051]. MM received a

\section{REFERENCES}

1. Sellarés J, de Freitas DG, Mengel M, Reeve J, Einecke G, Sis B, et al. Understanding the Causes of Kidney Transplant Failure: The Dominant Role of Antibody-Mediated Rejection and Nonadherence. Am J Transplant (2012) 12(2):388-99. doi: 10.1111/j.1600-6143.2011.03840.x

2. Matas AJ, Fieberg A, Mannon RB, et al. Long-term follow-up of the DeKAF cross-sectional cohort study. Am J Transplant (2019) 19(5):1432-43. doi: 10.1111/ajt.15204

3. Heilman RL, Nijim A, Desmarteau YM, et al. De novo donor-specific human leukocyte antigen antibodies early after kidney transplantation. Transplantation (2014) 98(12):1310-5. doi: 10.1097/TP.0000000000000216

4. Wiebe C, Gibson IW, Blydt-Hansen TD, Anglicheau D, Giral M, Bestard O, et al. Evolution and Clinical Pathologic Correlations of De Novo DonorSpecific HLA Antibody Post Kidney Transplant. Am J Transplant (2012) 12 (5):1157-67. doi: 10.1111/j.1600-6143.2012.04013.x

5. Coemans M, Süsal C, Döhler B, Anglicheau D, Giral M, Bestard O, et al. Analyses of the short- and long-term graft survival after kidney transplantation in Europe between 1986 and 2015. Kidney Int (2018) 94 (5):964-73. doi: 10.1016/j.kint.2018.05.018

6. Wiebe C, Nevins TE, Robiner WN, Thomas W, Matas AJ, Nickerson PW. The Synergistic Effect of Class II HLA Epitope-Mismatch and Nonadherence on Acute Rejection and Graft Survival. Am J Transpl (2015) 15(8):2197-202. doi: 10.1111/ajt.13341

7. Girerd S, Schikowski J, Girerd N, Duarte K, Busby H, Gambier N, et al. Impact of reduced exposure to calcineurin inhibitors on the development of de novo DSA: A cohort of non-immunized first kidney graft recipients between 2007 and 201411 Medical and Health Sciences 1103 Clinical Sciences. BMC Nephrol (2018) 19(1):232. doi: 10.1186/s12882-018-1014-2

8. Lim WH, Wong G, Heidt S, Claas FHJ. Novel aspects of epitope matching and practical application in kidney transplantation. Kidney Int (2018) 93(2):31424. doi: 10.1016/j.kint.2017.08.008

9. Kosmoliaptsis V, Sharples LD, Chaudhry AN, Halsall DJ, Bradley JA, Taylor CJ. Predicting HLA Class II Alloantigen Immunogenicity From the Number and Physiochemical Properties of Amino Acid Polymorphisms. Transplantation (2011) 91(2):183-90. doi: 10.1097/TP.0b013e3181ffff99

10. Kosmoliaptsis V, Mallon DH, Chen Y, Bolton E, Bradley J, Taylor C, et al. Alloantibody Responses After Renal Transplant Failure Can Be Better Predicted by Donor-Recipient HLA Amino Acid Sequence and fellowship grant from ESOT (European Society for Organ Transplantation).

\section{ACKNOWLEDGMENTS}

We acknowledge the assistance of our lab technicians for careful management of all biological samples, the staff of the flow cytometer technical support and of the biobank of our center. Samples from patients included in this study were provided by the Biobank HUB-ICO-IDIBELL (PT17/0015/0024), integrated in the Spanish Biobank Network and they were processed following standard operating procedures with the appropriate approval of the Ethics and Scientific Committees. We also thank all kidney transplant unit staff for their support and care of the patients.

\section{SUPPLEMENTARY MATERIAL}

The Supplementary Material for this article can be found online at: https://www.frontiersin.org/articles/10.3389/fimmu.2020. 623276/full\#supplementary-material

Physicochemical Disparities Than Conventional HLA Matching. Am J Transplant (2016) 16(7):2139-47. doi: 10.1111/ajt.13707

11. Duquesnoy RJ. HLA epitope based matching for transplantation. Transpl Immunol (2014) 31(1):1-6. doi: 10.1016/j.trim.2014.04.004

12. Wiebe C, Pochinco D, Blydt-Hansen TD, Ho J, Birk P, Karpinski M, et al. Class II HLA epitope matching-A strategy to minimize de novo donor-specific antibody development and improve outcomes. Am J Transplant (2013) 13 (12):3114-22. doi: 10.1111/ajt.12478

13. Sapir-Pichhadze R, Tinckam K, Quach K, Logan AG, Laupacis A, John R, et al. HLA-DR and -DQ Eplet Mismatches and Transplant Glomerulopathy: A Nested Case-Control Study. Am J Transplant (2015) 15(1):137-48. doi: 10.1111/ajt.12968

14. Wiebe C, Kosmoliaptsis V, Pochinco D, Gibson I, Ho J, Birk P, et al. HLA-DR/ DQ molecular mismatch: A prognostic biomarker for primary alloimmunity. Am J Transplant (2019) 19(6):1708-19. doi: 10.1111/ajt.15177

15. Lachmann N, Niemann M, Reinke P, Budde K, Schmidt D, Halleck F, et al. Donor Recipient Matching Based on Predicted Recognizable HLA Epitopes Predicts the Incidence of De Novo Donor-Specific HLA Antibodies Following Renal Transplantation. Am J Transplant (2017) 17(12):3076-86. doi: 10.1111/ ajt. 14393

16. Afzali B, Lechler RI, Hernandez-Fuentes MP. Allorecognition and the alloresponse: clinical implications. Tissue Antigens (2007) 69(6):545-56. doi: 10.1111/j.1399-0039.2007.00834.x

17. Geneugelijk K, Niemann M, Drylewicz J, van Zuilen AD, Joosten I, Allebes WA, et al. PIRCHE-II Is Related to Graft Failure after Kidney Transplantation. Front Immunol (2018) 9:321. doi: 10.3389/fimmu.2018.00321

18. Crespo E, Cravedi P, Martorell J, Luque S, Melilli E, Cruzado JM, et al. Posttransplant peripheral blood donor-specific interferon- $\gamma$ enzyme-linked immune spot assay differentiates risk of subclinical rejection and de novo donor-specific alloantibodies in kidney transplant recipients. Kidney Int (2017) 92(1):201-13. doi: 10.1016/j.kint.2016.12.024

19. Cherukuri A, Mehta R, Sharma A, Sood P, Zeevi A, Tevar AD, et al. Posttransplant donor specific antibody is associated with poor kidney transplant outcomes only when combined with both T-cell-mediated rejection and nonadherence. Kidney Int (2019) 96(1):202-13. doi: 10.1016/j.kint.2019.01.033

20. Ashoor I, Najafian N, Korin Y, Reed EF, Mohanakumar T, Ikle D, et al. Standardization and cross validation of alloreactive IFN $\gamma$ ELISPOT assays within the clinical trials in organ transplantation consortium. Am J Transplant (2013) 13(7):1871-9. doi: 10.1111/ajt.12286 
21. Bestard O, Crespo E, Stein M, Lúcia M, Roelen DL, de Vaal YJ, et al. Crossvalidation of IFN- $\gamma$ Elispot assay for measuring alloreactive memory/effector T cell responses in renal transplant recipients. Am J Transpl (2013) 13(7):188090. doi: 10.1111/ajt.12285

22. Heeger PS, Greenspan NS, Kuhlenschmidt S, et al. Pretransplant frequency of donor-specific, IFN-gamma-producing lymphocytes is a manifestation of immunologic memory and correlates with the risk of posttransplant rejection episodes. J Immunol (1999) 163(4):2267-75.

23. Nickel P, Presber F, Bold G, Biti D, Schönemann C, Tullius SG, et al. Enzymelinked immunosorbent spot assay for donor-reactive interferon-gammaproducing cells identifies $\mathrm{T}$-cell presensitization and correlates with graft function at 6 and 12 months in renal-transplant recipients. Transplantation (2004) 78(11):1640-6. doi: 10.1097/01.TP.0000144057.31799.6A

24. Crespo E, Lucia M, Cruzado JM, Luque S, Melilli E, Manonelles A, et al. Pretransplant donor-specific T-cell alloreactivity is strongly associated with early acute cellular rejection in kidney transplant recipients not receiving T-cell depleting induction therapy. PLoS One (2015) 10(2):e0117618. doi: 10.1371/ journal.pone.0117618

25. Konvalinka A, Tinckam K. Utility of HLA Antibody Testing in Kidney Transplantation. J Am Soc Nephrol (2015) 26(7):1489-502. doi: 10.1681/ ASN.2014080837

26. Haas M, Loupy A, Lefaucheur C, Roufosse C, Glotz D, Seron D, et al. The Banff 2017 Kidney Meeting Report: Revised diagnostic criteria for chronic active $\mathrm{T}$ cell-mediated rejection, antibody-mediated rejection, and prospects for integrative endpoints for next-generation clinical trials. Am J Transplant (2018) 18(2):293-307. doi: 10.1111/ajt.14625

27. Kramer CSM, Koster J, Haasnoot GW, Roelen DL, Claas FHJ, Heidt S. HLAEMMA: A user-friendly tool to analyse HLA class I and class II compatibility on the amino acid level. HLA 96(1):43-51. doi: 10.1111/tan.13883

28. Geneugelijk K, Hönger G, van Deutekom HWM, Thus KA, Keşmir C, Hösli I, et al. Predicted Indirectly Recognizable HLA Epitopes Presented by HLADRB1 Are Related to HLA Antibody Formation During Pregnancy. Am J Transplant (2015) 15(12):3112-22. doi: 10.1111/ajt.1350

29. Montero N, Farouk S, Gandolfini I, Crespo E, Jarque M, Meneghini M, et al. Pretransplant Donor-specific IFN $\gamma$ ELISPOT as a Predictor of Graft Rejection. Transplant Direct (2019) 5(5):e451. doi: 10.1097/TXD.0000000000000886

30. Grifoni A, Weiskopf D, Ramirez SI, Mateus J, Dan JM, Moderbacher CR, et al. Targets of T Cell Responses to SARS-CoV-2 Coronavirus in Humans with COVID-19 Disease and Unexposed Individuals. Cell (2020) 181(7):148901.e15. doi: 10.1016/j.cell.2020.05.015

31. Wiebe C, Rush DN, Nevins TE, Birk PE, Blydt-Hansen T, Gibson IW, et al. Class II Eplet Mismatch Modulates Tacrolimus Trough Levels Required to Prevent Donor-Specific Antibody Development. J Am Soc Nephrol (2017) 28 (11):3353-62. doi: 10.1016/j.kint.2019.01.033. ASN.2017030287.

32. Gebauer BS, Hricik DE, Atallah A, Bryan K, Riley J, Tary-Lehmann M, et al. Evolution of the enzyme-linked immunosorbent spot assay for posttransplant alloreactivity as a potentially useful immune monitoring tool. Am J Transplant (2002) 2(9):857-66. doi: 10.1034/j.1600-6143.2002.20908.x
33. Wiebe C, Rush DN, Gibson IW, Pochinco D, Birk PE, Goldberg A, et al. Evidence for the alloimmune basis and prognostic significance of Borderline $\mathrm{T}$ cell-mediated rejection. Am J Transplant (2020) 00:1-10. doi: 10.1111/ ajt. 15860

34. Senev A, Coemans M, Lerut E, Van Sandt V, Kerkhofs J, Daniëls L, Driessche MV, et al. Eplet Mismatch Load and De Novo Occurrence of Donor-Specific Anti-HLA Antibodies, Rejection, and Graft Failure after Kidney Transplantation: An Observational Cohort Study. J Am Soc Nephrol (2020) 31(9):2193-204. doi: 10.1681/ASN.2020010019. ASN.2020010019.

35. Tambur AR, McDowell H, Hod-Dvorai R, Abundis MAC, Pinelli DF. The quest to decipher HLA immunogenicity: Telling friend from foe. Am J Transpl (2019) 19(10):2910-25. doi: 10.1111/ajt.15489

36. Baker RJ, Hernandez-Fuentes MP, Brookes PA, Chaudhry AN, Cook HT, Lechler RI. Loss of Direct and Maintenance of Indirect Alloresponses in Renal Allograft Recipients: Implications for the Pathogenesis of Chronic Allograft Nephropathy. J Immunol (2001) 167(12):7199-206. doi: 10.4049/ jimmunol.167.12.7199

37. Shiu KY, Mclaughlin L, Rebollo-Mesa I, Zhao J, Semik V, Cook HT, et al. Blymphocytes support and regulate indirect T-cell alloreactivity in individual patients with chronic antibody-mediated rejection. Kidney Int (2015) 88 (3):560-8. doi: 10.1038/ki.2015.100

38. Herrera OB, Golshayan D, Tibbott R, Salcido Ochoa F, James MJ, MarelliBerg FM, et al. A Novel Pathway of Alloantigen Presentation by Dendritic Cells. J Immunol (2004) 173(8):4828-37. doi: 10.4049/jimmunol.173.8.4828

39. Bestard O, Nickel P, Cruzado JM, Schoenemann C, Boenisch O, Sefrin A, et al. Circulating Alloreactive $\mathrm{T}$ Cells Correlate with Graft Function in Longstanding Renal Transplant Recipients. J Am Soc Nephrol (2008) 19 (7):1419-29. doi: 10.1681/ASN.2007050539

40. Hughes AD, Zhao D, Dai H, Abou-Dayaor K, Tieu R, Rammal R, et al. Crossdressed dendritic cells sustain effector $\mathrm{T}$ cell responses in islet and kidney allografts. J Clin Invest (2019) 130(1):287-94. doi: 10.1172/JCI125773

Conflict of Interest: MN is an employee of PIRCHE AG that runs the PIRCHE web-portal.

The remaining authors declare that the research was conducted in the absence of any commercial or financial relationships that could be construed as a potential conflict of interest.

Copyright (C) 2021 Meneghini, Crespo, Niemann, Torija, Lloberas, Pernin, Fontova, Melilli, Favà, Montero, Manonelles, Cruzado, Palou, Martorell, Grinyó and Bestard. This is an open-access article distributed under the terms of the Creative Commons Attribution License (CC BY). The use, distribution or reproduction in other forums is permitted, provided the original author(s) and the copyright owner(s) are credited and that the original publication in this journal is cited, in accordance with accepted academic practice. No use, distribution or reproduction is permitted which does not comply with these terms. 